\title{
Arachidonic acid metabolites in pathogenic yeasts
}

\author{
Ruan Ells ${ }^{1}$, Johan LF Kock', Jacobus Albertyn ${ }^{1}$ and Carolina H Pohl ${ }^{1,2^{*}}$
}

\begin{abstract}
Although most of what is known about the biology and function of arachidonic acid metabolites comes from the study of mammalian biology, these compounds can also be produced by lower eukaryotes, including yeasts and other fungi. It is also in this group of organisms that the least is known about the metabolic pathways leading to the production of these compounds as well as the functions of these compounds in the biology of fungi and yeasts. This review will deal with the discovery of oxylipins from polyunsaturated fatty acids, and more specifically the arachidonic acid derived eicosanoids, such as 3-hydroxy eicosatetraenoic acid, prostaglandin $\mathrm{F}_{2 \mathrm{a}}$ and prostaglandin $E_{2}$, in yeasts starting in the early 1990s. This review will also focus on what is known about the metabolic pathways and/or proteins involved in the production of these compounds in pathogenic yeasts. The possible roles of these compounds in the biology, including the pathology, of these organisms will be discussed.
\end{abstract}

Keywords: Arachidonic acid, Oxylipins, Pathogenic, Yeasts

\section{Introduction}

Fatty acids are the main components of lipids and play a key role as structural components of cellular membranes, affecting the physical state of the membranes, as storage lipids and as signaling molecules that impact the immune system in various ways [1]. Oxylipins is the collective term for oxygenated polyunsaturated fatty acids (PUFAs) and metabolites and includes the eicosanoids, which are an important group of oxygenated C20 PUFAs [2]. These compounds represent the prostaglandins, thromboxanes, prostacyclins, leukotrienes, lipoxins, hepoxilins, hydro (pero)xy fatty acids, hydroxylated fatty acids and epoxy derivatives [3,4]. In mammalian cells they are mainly synthesized from eicosatrienoic acid [20:3(n-6), dihomo$\gamma$-linolenic acid (DGLA)], eicosatetraenoic acid [20:4(n-6), arachidonic acid (AA)] and eicosapentaenoic acid [20:5 (n-3), EPA] [3] as well as from docosahexaenoic acid [22:6(n-3), DHA] [5]. They are synthesized through the actions of cyclooxygenases (COX) [6], lipoxygenases (LOX) [7], cytochrome P450s (CYP450s) [4,8,9], or nonenzymatic pathways [10]. However, in fungi the precursors for oxylipin production are usually octadecenoic acid

\footnotetext{
* Correspondence: PohlCH@ufs.ac.za

'Department of Microbial, biochemical and food Biotechnology, University of the Free State, Bloemfontein 9300, South Africa

${ }^{2}$ Department of Microbial, biochemical and food Biotechnology, University of the Free State, PO Box 339, Bloemfontein 9300, South Africa
}

[18:1(n-9), oleic acid], octadecadienoic acid [18:2(n-6), linoleic acid] and octadecatrienoic acid [18:3(n-3), linolenic acid] [11].

Most of what is known about oxylipins, such as eicosanoids, comes from the investigation of mammalian biology and very little is known about the biochemistry of eicosanoid production in the lower organisms, including yeasts. This review will focus on the occurrence of arachidonic acid derived oxylipins in pathogenic yeast, known metabolic pathways for the production of these oxylipins as well as the possible roles and significance of these compounds in the biology of pathogenic yeasts.

\section{Occurrence of eicosanoids in pathogenic yeasts}

In the early 1990's the presence of AA metabolites (including prostaglandins and 3-hydroxy $(\mathrm{OH})$ fatty acids) in environmental yeasts belonging to the Dipodascaceae and Lipomycetaceae families was discovered [12-17]. Following this discovery, AA metabolites were also implicated in the pathogenesis of certain yeasts. Although, host cells produce eicosanoids, the pathogen can also contribute to this production. The production of a $3-\mathrm{OH}$ fatty acid from exogenous AA was found in the pathogenic yeast, Candida albicans $[18,19]$. This compound was identified by GC-MS as 3,18-dihydroxy5,8,11,14-eicosatetraenoic acid (3,18 di-HETE) and 
was associated with the hyphal forms, possibly playing a role in morphogenesis and pathogenicity. In biofilms of the closely related yeast, $C$. dubliniensis, the production of 3,18 di-HETE from exogenous AA was also found [20].

Noverr and co-workers [21] indicated by the use of ELISA assays that the pathogenic yeasts, C. albicans and Cryptococcus neoformans, have the ability to produce and secrete prostaglandins (PGs) de novo and that the addition of exogenous AA increased this production significantly. They referred to it as $\mathrm{PGE}_{\mathrm{x}}$ due to the crossreactivity observed with prostaglandins of the $\mathrm{E}$ class using prostaglandin immunoassays. Later, using mass spectrometry, it was verified as $\mathrm{PGE}_{2}[22,23]$. Candida albicans and Crypt. neoformans can also produce other prostaglandins, including $\mathrm{PGD}_{2}$ and $\mathrm{PGF}_{2 \alpha}$ as well as leukotrienes (LTB4, cysteinyl leukotrienes) from exogenous AA [24]. Similar results were obtained by ErbDownward and co-workers [25] in Crypt. neoformans, however lysates from this yeast produced more $\mathrm{PGF}_{2 \alpha}$ compared to $\mathrm{PGE}_{2}$, in contrast to C. albicans, where $\mathrm{PGE}_{2}$ was the main prostaglandin produced. This eicosanoid production was found for planktonic cells, however the production of $\mathrm{PGE}_{2}$, sensitive to $\mathrm{COX}$ inhibitors, de novo by $C$. albicans biofilms has also been reported $[26,27]$. The COX inhibitors used in the latter study also inhibited biofilm formation. Interestingly, the addition of $\mathrm{PGE}_{2}$ together with acetylsalicylic acid (aspirin, ASA) completely removed biofilm inhibition by ASA. The authors concluded that biofilm development, morphogenesis and regulation of physiological processes in this yeast are regulated by COX-dependent synthesis of fungal prostaglandins.

During the last few years there has also been an increase in other non-albicans Candida species as opportunistic human pathogens [28]. These include C. dubliniensis, C. glabrata, C. krusei, C. tropicalis and C. parapsilosis. Recently, it was found that C. dubliniensis, C. glabrata and C. tropicalis are also capable of producing $\mathrm{PGE}_{2}[29,30]$. Candida albicans, C. dubliniensis and C. tropicalis produced considerable amounts of $\mathrm{PGE}_{2}$ whereas C. glabrata produced only trace amounts. Interestingly, in the presence of human keratinocytes, important in cutaneous immune responses, C. albicans, C. tropicalis as well as C. glabrata produced 10 -fold more $\mathrm{PGE}_{2}$ with the keratinocytes alone producing only trace amounts of $\mathrm{PGE}_{2}$. This indicates the involvement of $\mathrm{PGE}_{2}$ during host pathogen interactions, specifically during superficial infections.

The pathogenic dimorphic yeast, Paracoccidioides brasiliensis, also produced prostaglandins from endogenous and exogenous AA [31,32]. The use of COX inhibitors, indomethacin and piroxicam, not only decreased prostaglandin production but also viability of the yeast.

\section{Biosynthesis of yeast eicosanoids}

The biosynthetic pathway for eicosanoid production in mammalian cells has been well studied and is used as a model to try and identify enzymes involved in this pathway in lower organisms, including fungi. The specific AA metabolites produced in vivo in mammalian cells are dependent upon the most active enzymes in specific tissues [33]. Cyclooxygenases, LOX, CYP450s and $\beta$-oxidation enzymes are known to add hydroxyl groups to AA [34].

Limited information is, however, available regarding the mechanisms involved in eicosanoid production in yeasts. Enzymatic involvement in these pathways was indicated by incubating AA together with boiled lysates of either C. albicans or Crypt. neoformans [22,23,25]. This lead to a significant reduction in $\mathrm{PGE}_{2}$ produced, suggesting the presence of a denaturable enzymatic pathway in these yeasts. Brodhun and Feussner [35] speculated about the unlikelihood of the existence of a specific prostaglandin pathway in fungi. They ascribed these reactions to be similar to a known isoprostane type of non-specific lipid peroxidation reaction that can be catalyzed by any protein harboring iron as cofactor.

The use of different enzyme inhibitors is widely applied in order to identify the pathways and putative enzymes involved in eicosanoid production by fungi. There are a number of studies that used COX inhibitors, including ASA and other non-steroidal anti-inflammatory drugs (NSAIDs), as well as LOX inhibitors, to identify possible mechanisms involved in fungal eicosanoid production $[15,25,36,37]$, however this has not been able to provide conclusive evidence.

\section{Candida albicans}

Initially Noverr and co-workers [21] speculated that COX-like enzymes had to be present in C. albicans. In their studies they used different COX inhibitors (i.e. etodolac, indomethacin and piroxicam), to evaluate prostaglandin production. They found that all these inhibitors not only decreased prostaglandin production but also decreased the viability of these cells. This suggests that the decrease was not due to a specific inhibition of the enzyme but rather due to an effect on cell viability or that prostaglandin production could regulate the viability of the yeast [22]. Later, using non-selective mammalian COX inhibitors, ASA, indomethacin and resveratrol, and the LOX inhibitor, nordihydroguaiaretic acid (NDGA) (also known as a COX inhibitor) the production of $\mathrm{PGE}_{2}$ was reduced without affecting viability [23]. Similar results were obtained for $C$. albicans and $C$. dubliniensis biofilms using ASA and NDGA [29]. However, the use of the selective COX-2 inhibitor, CAY10404 [3-(4-methyl sulphonylphenyl)-4-phenyl-5-trifluoromethylisoxazole], had no effect on $\mathrm{PGE}_{2}$ production, suggesting that enzymes distinct from mammalian COX and LOX are responsible for 
$\mathrm{PGE}_{2}$ production in C. albicans [23]. This agrees with the BLAST results used to search the genomes of $C$. albicans for COX and LOX homologues, which did not reveal any sequences with significant homology to mammalian COX and LOX $[38,39]$. This was followed by the identification of two non-COX/LOX-related enzymes, involved in $\mathrm{PGE}_{2}$ production in C. albicans [23]. These enzymes were identified as a fatty acid desaturase, Ole2p, and a multicopper oxidase or laccase homologue, Fet3p. The importance of these enzymes was illustrated by indicating that mutants lacking the OLE2 or FET3 gene had a reduced production of $\mathrm{PGE}_{2}$. However, this did not completely inhibit $\mathrm{PGE}_{2}$ production, suggesting that other enzymes are also involved.

Recently, the involvement of multicopper oxidases in the production of $\mathrm{PGE}_{2}$ by both $C$. albicans and $C$. dubliniensis biofilms, as well as the possible role of CYP450s in prostaglandin production, possibly upstream of the multicopper oxidases were also indicated [29]. This was done using different CYP450 inhibitors [6-(2-propargyloxyphenyl) hexanoic acid and 1-aminobenzotriazole] and multicopper oxidase inhibitors (ammonium tetrathiomolybdate and sodium azide). These inhibitors significantly decreased $\mathrm{PGE}_{2}$ production without affecting cell biomass and viability of C. albicans and C. dubliniensis biofilms. The availability of the genomes indicated the presence of 12 CYP450s in C. albicans and 10 CYP450s in C. dubliniensis compared to the only 3 in S. cerevisiae [40]. This may indicate the involvement of CYP450s in pathogenesis.

\section{Cryptococcus neoformans}

Since the COX inhibitor, indomethacin, could reduce prostaglandin production in Crypt. neoformans, it was initially speculated that the enzyme involved was COXrelated [21]. However, similar to C. albicans, the genome of Crypt. neoformans did not reveal any sequence homology to mammalian COX and LOX $[22,25]$. The study by Erb-Downward and Huffnagle [22] did not observe this inhibitory effect in the presence of the COX inhibitors, ASA and indomethacin, suggesting that other nonCOX enzymes are involved. It must, however, be noted that the difference in especially incubation time used in the latter study, may have contributed to the observed difference in results.

In another study, Erb-Downward and co-workers [25] indicated that the polyphenolic LOX inhibitors, caffeic acid, NDGA and resveratrol inhibited both $\mathrm{PGE}_{2}$ and $\mathrm{PGF}_{2 \alpha}$ production in Crypt. neoformans, even though a LOX homologue is absent. This lead to the identification of a multicopper oxidase, laccase, known to bind polyphenols, as an enzyme involved in prostaglandin production in Crypt. neoformans. Laccase alone did not convert the $\mathrm{PGE}_{2}$ precursors (AA or $\mathrm{PGH}_{2}$ ) to $\mathrm{PGG}_{2}$ or new prostaglandins, but it did convert $\mathrm{PGG}_{2}$ to $\mathrm{PGE}_{2}$ and 15-
keto-PGE ${ }_{2}$. This suggests that multicopper oxidases might play a significant role in eicosanoid production by this pathogenic yeast. However, it is not the only enzyme involved, and questions still need to be answered regarding the enzymes upstream of the multicopper oxidase. In addition, it has been speculated that enzymes belonging to the Old Yellow Enzyme family might be involved in this pathway, leading to the production of $\mathrm{PGF}_{2 \alpha}$ from $\mathrm{PGE}_{2}[25]$.

\section{Paracoccidioides brasiliensis}

Similar to C. albicans and Crypt. neoformans, it is speculated that a COX pathway is involved in the production of prostaglandin by the dimorphic yeast, $P$. brasiliensis $[31,32]$. This was indicated by the use of indomethacin and piroxicam, which not only inhibited prostaglandin production but also fungal viability. The authors suggest a COX-dependent metabolic pathway is involved and that, similar to C. albicans, prostaglandins have a possible role in fungal survival.

\section{Biological activity of eicosanoids}

The production of eicosanoids by mammalian cells is in response to mechanical factors or chemical stimuli, such as cytokines, or in response to pathogen invasion [41]. They act similar to hormones, as potent biological regulators and are involved in many systems such as the cardiovascular, renal, reproduction and the immune system $[42,43]$. The immunomodulatory properties of eicosanoids have been studied intensively in mammalian cells with a single eicosanoid capable of having pleiotropic functions $[41,44]$. This includes different physiological and pharmacological effects on different cell types. These effects are mainly due to the existence of multiple receptors for each lipid species on plasma membranes. Eicosanoids are known to function through G-proteincoupled receptors (GPCRs), known as guanine nucleotide regulatory proteins, to elicit their pharmacological and signaling profiles $[3,44]$. The activated trimeric G-proteins affect the concentrations of the second messengers, cyclic AMP (cAMP), or intracellular ions such as $\mathrm{K}^{+}$. This occurs through the stimulation or inhibition of adenylate cyclase or the opening or closing of $\mathrm{K}^{+}$channels.

$\mathrm{CD}_{4}^{+} \mathrm{T}$ cells differentiate into $\mathrm{CD}_{4}^{+} \mathrm{T}$ helper (Th) cells, Th1 or Th2, in response to antigens or cytokines to eliminate pathogens [45]. These Th cells secrete different cytokines and have different functions during an immune response. The Th1 cytokines are involved in activating macrophages and cytotoxic $\mathrm{T}$ cells, known as cell-mediated/protective immunity against intracellular pathogens [46]. In addition, the Th2 cytokines are involved in humoral immunity by helping B cells to produce antibodies. However, an imbalance in Th1/Th2 responses can be detrimental to the host, leading to 
serious autoimmune diseases while these responses can also negatively regulate each other [47]. Interestingly, pathogen studies suggested that eicosanoid production, especially $\mathrm{PGE}_{2}$, could shift these Th responses in favor of the pathogen $[47,48]$. Therefore, the activation of Th1 and/or Th2 responses may correlate to the occurrence of resistance and susceptibility to infections.

Both host and pathogen are capable of producing $\mathrm{PGE}_{2}$ during an infection indicating that both can modulate immune responses $[48,49]$. These biological effects of prostaglandins on the immune system and the enhanced production of prostaglandins and leukotrienes by pathogenic yeasts may lead to the intracellular survival followed by chronic and disseminated infections [50]. This can be illustrated by the ability of these eicosanoids to downregulate macrophage functions as mentioned above for mammalian eicosanoids.

Candida infections stimulate both the innate and adaptive immune responses [51-53]. Although several studies indicated that C. albicans and Crypt. neoformans stimulate the production of Th1-type cytokines leading to protective immunity or acquired resistance against these pathogens [53-57], the production of $\mathrm{PGE}_{2}$ during infections inhibits Th1 responses and has an inducing effect on Th2 and Th17 responses [49,58,59]. It is known that Th1 responses are critical for protection against candidiasis whereas Th2 responses are less important [60]. Additionally, Th2 responses are non-protective against pathogens and lead to chronic or disseminated infections [51]. Th17 responses play an important role in autoimmune diseases as well as the control of fungal infections by initiating and maintaining inflammation [61]. Additionally, the uncontrolled production of Th17 cytokines can be harmful to the host during systemic infections [59]. Candida albicans $\mathrm{PGE}_{2}$ enhances Th17 responses by stimulating the production of IL-17 and IL-22. Similarly, the monocyte subset, $\mathrm{CD} 14^{++} \mathrm{CD} 16^{-}$, produce more $\mathrm{PGE}_{2}$ and also induces a greater Th17 response compared to the other monocyte subsets, $\mathrm{CD}_{14}{ }^{+} \mathrm{CD} 16^{+}$, in response to $C$. albicans [62]. The Th17 responses are induced by the presence of the pathogen associated molecular patterns, mannan and $\beta$-glucan from C. albicans $[61,63]$. So the production of $\mathrm{PGE}_{2}$ during infections might be beneficial for the pathogens. Another important factor induced by $\mathrm{PGE}_{2}$, is tissue eosinophilia, leading to tissue damage, which is a common feature of some chronic fungal infections [49].

The $\mathrm{PGE}_{\mathrm{x}}\left(\mathrm{PGE}_{2}\right)$ produced by both $C$. albicans and Crypt. neoformans was found to be biologically active on both yeast and mammalian cells $[21,64]$. It had immunosuppressive effects in mammalian cells by downmodulating chemokine production, tumor necrosis factor alpha (TNF $\alpha)$ production and splenocyte proliferation while up-regulating IL-10 production (Th2 responses).
The biological activity on yeast was indicated through the stimulation of germination in C. albicans, similar to synthetic $\mathrm{PGE}_{2}$ and thromboxane $\mathrm{B}_{2}\left(\mathrm{TXB}_{2}\right)$ [64]. Similar results were obtained by Kalo-Klein and Witkin [65] using commercial $\mathrm{PGE}_{2}$, suggesting that morphogenesis (yeastto-hyphae transition) is induced in C. albicans by a $\mathrm{PGE}_{2}$ caused increase in cAMP levels. The increase in intracellular cAMP levels in guinea-pig tracheal epithelial cells due to commercial $\mathrm{PGE}_{2}$ was also observed [66]. However, other prostaglandins i.e. $\mathrm{PGI}_{2}, \mathrm{PGF}_{2 \alpha}$ and $\mathrm{PGD}_{2}$ did not exert any effect on cAMP. Interestingly, $\mathrm{PGF}_{2 \alpha}$ had no effect on germination of C. albicans [65]. This suggests that the other prostaglandins, $\mathrm{PGI}_{2}$ and $\mathrm{PGD}_{2}$, may also not affect germination by $C$. albicans. The $\mathrm{PGE}_{2}$ precursor, $\mathrm{AA}$ as well as other long chain fatty acids (i.e. C18 fatty acids) did not have any effect on germination [64].

Morphogenesis in pathogenic fungi is often associated with increased virulence and mucosal invasiveness [67] and the start of biofilm formation, with infections by C. albicans mainly caused by biofilms [68]. This suggests that prostaglandin production, especially $\mathrm{PGE}_{2}$, might be an important virulence factor. However, the exact role of prostaglandins in morphogenesis and biofilm development is complex and remains unclear. Although, Alem and Douglas [27] indicated the production of $\mathrm{PGE}_{2}$ by $C$. albicans biofilms, $\mathrm{PGE}_{2}$ did not function as a QS molecule, with no correlation found between $\mathrm{PGE}_{2}$ production and cell density. In addition, 3,18-diHETE was shown, through immunofluorescence microscopy using a polyclonal antibody, specific against chemically synthesized 3-OH fatty acids [69], to be mainly associated with the hyphal forms of $C$. albicans and not the yeast form [18]. This might play a role in the anchorage of these cells to host cells during infections. This indicates that $3-\mathrm{OH}$ fatty acid production may be an important virulence factor in C. albicans as well as in C. dubliniensis, since 3,18diHETE production has also been found in this closely related yeast [20]. Interestingly, the related 3-OH AA metabolite, 3R-HETE, produced by the non-pathogenic yeast $D$. uninucleata, was also reported to have proinflammatory actions in mammalian cells by affecting signal transduction processes in human neutrophils and tumor cells [70,71]. Ciccoli and co-workers [72] also indicated that 3-HETE can be used as a substrate for mammalian COX-2, activated by C. albicans in a HeLa infection model [73], to produce pro-inflammatory 3-OH $\mathrm{PGE}_{2}$. This metabolite increased inflammation in host cells. The immunomodulatory activities of this compound were illustrated through the increased upregulation of IL6 gene expression (an enhanced Th2 response), in comparison to $\mathrm{PGE}_{2}$, as well as cAMP levels, similar to $\mathrm{PGE}_{2}$, in Jurkat T-cells and lung adenocarcinoma cells (A549 cells), respectively $[49,72]$. 


\section{Conclusions}

This review indicates that AA metabolites are widely distributed in the fungal domain. The limited available knowledge about the possible pathways or enzymes involved in fungal eicosanoid production compared to mammalian cells, is evident. In addition, when COX and LOX inhibitors are used to identify the pathways involved, it should be noted that these inhibitors are non-selective, therefore they could inhibit various enzymes needed for fungal viability, thus leading to cell death. The so called nonprostaglandin mediated effects by different NSAIDs have been indicated before in mammalian cells [74]. These include the interactions of NSAIDs with biological membranes and influencing important cell functions such as transmembrane anion transport, oxidative phosphorylation, enzyme activity as well as the uptake of AA. These mechanisms, together with the effect of ASA on the mitochondrial activity of various yeasts [75], might provide a possible explanation for the observed effects in the different studies. Additionally, some of these inhibitors used, such as NDGA, also have antioxidative properties which could also lead to the observed decrease in prostaglandin production [76].

The statement that $\mathrm{PGE}_{2}$ is responsible or involved in fungal viability should be interpreted with care. Although, Alem and Douglas [26] as well as de Quadros and co-workers [77] indicated that NSAID mediated inhibition of biofilm formation by $C$. albicans can be overcome by the addition of $\mathrm{PGE}_{2}$, the exact role of $\mathrm{PGE}_{2}$ during $C$. albicans biofilm formation is still unclear and needs further investigation.

The importance of eicosanoids during host pathogen interactions was also emphasized. More specifically, the immune response, the system that is responsible for protecting us against pathogens, can be altered through the production of eicosanoids. The production of these lipid mediators functions as components of a complex chemical signaling system between host and pathogen. Additionally, the effects of prostaglandins and their fatty acid precursors might be species specific, but that it does play an important role during pathogenesis cannot be ignored.

\section{Competing interests}

The authors declare that they have no competing interests.

\section{Authors' contributions}

CHP was responsible for the layout and initial idea for the manuscript. RE and CHP wrote the manuscript. JLFK and JA participated in researching the literature and critical discussion of the work. All authors read and approved the final manuscript.

\section{Acknowledgements}

This work was supported by the National Research Foundation, South Africa (Grant numbers TTK2007041000014 and BS2008092300002).

Received: 19 June 2012 Accepted: 3 August 2012

Published: 8 August 2012

\section{References}

1. Van Bogaert INA, Groeneboer S, Saerens K, Soetaert W: The role of cytochrome P450 monooxygenases in microbial fatty acid metabolism. FEBS J 2011, 278:206-221.

2. Kock JLF, Strauss CJ, Pohl CH, Nigam S: The distribution of 3-hydroxy oxylipins in fungi. Prostag Oth Lipid M 2003, 71:85-96.

3. Smith WL: The eicosanoids and their biochemical mechanism of action. Biochem J 1989, 259:315-324.

4. Zeldin DC: Epoxygenase pathways of arachidonic acid metabolism. J Biol Chem 2001, 276:36059-36062.

5. Serhan CN, Arita M, Hong S, Gotlinger K: Resolvins, docosatrienes, and neuroprotectins, novel omega-3-derived mediators, and their endogenous aspirin-triggered epimers. Lipids 2004, 39:1125-1132.

6. Murakami M, Kudo I: Recent advances in molecular biology and physiology of the prostaglandin $\mathrm{E}_{2}$-biosynthetic pathway. Prog Lipid Res 2004, 43:3-35.

7. Henderson WR: The role of leukotrienes in inflammation. Ann Intern Med 1994, 121:684-697.

8. Carroll MA, McGiff JC: A new class of lipid mediators: cytochrome P450 arachidonate metabolites. Thorax 2000, 55:S13-S16.

9. Zhu Y, Schieber EB, McGiff JC, Balazy M: Identification of arachidonate P-450 metabolites in human platelet phospholipids. Hypertension 1995, 25:854-859.

10. Buczynski MW, Dumlao DS, Dennis ED: Thematic review series: proteomics. An integrated omics analysis of eicosanoid biology. J Lipid Res 2009, 50:1015-1038.

11. Tsitsigiannis DI, Keller NP: Oxylipins as developmental and host-fungal communication signals. Trends Microbiol 2007, 15:109-118.

12. Botha A, Kock JLF, van Dyk MS, Coetzee DJ, Augustyn OPH, Botes PJ: Yeast eicosanoids. IV. Evidence for prostaglandin production during ascosporogenesis by Dipodascopsis tóthii. System Appl Microbiol 1993, 16:159-163.

13. Coetzee DJ, Kock JLF, Botha A, van Dyk MS, Smit EJ, Botes PJ, Augustyn $\mathrm{OPH}$ : The distribution of arachidonic acid metabolites in the life cycle of Dipodascopsis uninucleata. System Appl Microbiol 1992, 15:311-318.

14. Fox SR, Hamberg M, Friend J, Ratledge C: Evidence for the mitochondrial biosynthesis of $3 R$-Hydroxy-5Z,8Z,11Z,14Z-eicosatetraenoic acid in the yeast Dipodascopsis uninucleata. Lipids 2000, 35:1205-1214.

15. Kock JLF, Coetzee DJ, van Dyk MS, Truscott M, Botha A, Augustyn OP: Evidence for, and taxonomic value of, an arachidonic acid cascade in the Lipomycetaceae. Antonie Leeuwenhoek 1992, 62:251-259.

16. Kock JLF, Coetzee DJ, van Dyk MS, Truscott M, Cloete FC, van Wyk V, Augustyn OPH: Evidence for pharmacologically active prostaglandins in yeasts. S Afr J Sci 1991, 87:73-75.

17. Van Dyk MS, Kock JLF, Coetzee DJ, Augustyn OPH, Nigam S: Isolation of a novel arachidonic acid metabolite 3-hydroxy-5,8,11,14-eicosatetraenoic acid (3-HETE) from the yeast Dipodascopsis uninucleata. FEBS Lett 1991, 283:195-198.

18. Deva R, Ciccoli R, Kock JLF, Nigam S: Involvement of aspirin-sensitive oxylipins in vulvovaginal candidiasis. FEMS Microbiol Lett 2001, 198:37-43.

19. Deva R, Ciccoli R, Schewe T, Kock JLF, Nigam S: Arachidonic acid stimulates cell growth and forms a novel oxygenated metabolite in Candida albicans. Biochim Biophys Acta 2000, 1486:299-311.

20. Ells R: The effect of arachidonic acid on lipid metabolism and biofilm formation of two closely related Candida species:: Magister Scientiae dissertation. University of the Free State, Department of Microbial, Biochemical and Food Biotechnology; 2008.

21. Noverr MC, Phare SM, Toews GB, Coffey MJ, Huffnagle GB: Pathogenic yeasts Cryptococcus neoformans and Candida albicans produce immunomodulatory prostaglandins. Infect Immun 2001, 69:2957-2963.

22. Erb-Downward JR, Huffnagle GB: Cryptococcus neoformans produces authentic prostaglandin $E_{2}$ without a cyclooxygenase. Eukaryot Cell 2007, 6:346-350.

23. Erb-Downward JR, Noverr MC: Characterization of prostaglandin $E_{2}$ production by Candida albicans. Infect Immun 2007, 75:3498-3505.

24. Noverr MC, Toews GB, Huffnagle GB: Production of prostaglandins and leukotrienes by pathogenic fungi. Infect Immun 2002, 70:400-402.

25. Erb-Downward JR, Noggle RM, Williamson PR, Huffnagle GB: The role of laccase in prostaglandin production by Cryptococcus neoformans. Mol Microbiol 2008, 68:1428-1437. 
26. Alem MAS, Douglas LJ: Effects of aspirin and other nonsteroidal antiinflammatory drugs on biofilms and planktonic cells of Candida albicans. Antimicrob Agents Chemother 2004, 48:41-47.

27. Alem MAS, Douglas LJ: Prostaglandin production during growth of Candida albicans biofilms. J Med Microbiol 2005, 54:1001-1005.

28. Segal E: Candida, still number one - what do we know and where are we going from there? Mycoses 2005, 48:3-11.

29. Ells R, Kock JLF, Albertyn J, Kemp G, Pohl CH: Effect of inhibitors of arachidonic acid metabolism on prostaglandin $E_{2}$ production by Candida albicans and Candida dubliniensis biofilms. Med Microbiol Immunol 2011 200:23-28.

30. Shiraki $Y$, Ishibashi $Y$, Hiruma M, Nishikawa A, Ikeda S: Candida albicans abrogates the expression of interferon- $\gamma$-inducible protein-10 in human keratinocytes. FEMS Immunol Med Microbiol 2008, 54:122-128.

31. Biondo GA, Dias-Melicio LA, Bordon-Graciani AP, Acorci-Valério MJ, Soares AMVC: Paracoccidioides brasiliensis uses endogenous and exogenous arachidonic acid for $\mathrm{PGE}_{\mathrm{x}}$ production. Mycopathologia 2010, 170:123-130

32. Bordon AP, Dias-Melicio LA, Acorci MJ, Biondo GA, Fecchio D, Peraçoli MTS Soares AMVC: Prostaglandin $E_{2}$ production by high and low virulent strains of Paracoccidioides brasiliensis. Mycopathologia 2007, 163:129-135.

33. Konturek SJ, Pawlik W: Physiology and pharmacology of prostaglandins. Dig Dis Sci 1986, 31:6S-19S.

34. Yilmaz E: Biotechnological production of prostaglandin. Biotech Adv 2001, 19:387-397.

35. Brodhun F, Feussner I: Oxylipins in fungi. FEBS J 2011, 278:1047-1063.

36. Botha A, Kock JLF, Nigam S: The production of eicosanoid precursors by mucoralean fungi. Adv Exp Med Biol 1997, 433:227-229.

37. Lamacka M, Sajbidor J: The content of prostaglandins and their precursors in Mortierella and Cunninghamella species. Lett Appl Microbiol 1998, 26:224-226.

38. Haas-Stapleton EJ, Lu Y, Hong S, Arita M, Favoreto S, Nigam S, Serhan CN, Agabian N: Candida albicans modulates host defense by biosynthesizing the pro-resolving mediator Resolvin E1. PLoS One 2007, 2:e1316.

39. Tsitsigiannis DI, Kowieski TM, Zarnowski R, Keller NP: Three putative oxylipin biosynthetic genes integrate sexual and asexual development in Aspergillus nidulans. Microbiology 2005, 151:1809-1821.

40. Park J, Lee S, Choi J, Ahn K, Park B, Park J, Kang S, Lee Y-H: Fungal cytochrome P450 database. BMC Genomics 2008, 9:402.

41. Funk CD: Prostaglandins and leukotrienes: advances in eicosanoid biology. Science 2001, 294:1871-1875.

42. Goodwin JS, Ceuppens J: Regulation of the immune response by prostaglandins. J Clin Immunol 1983, 3:295-315.

43. Lamačka M, Šajbidor J: Biotechnological production of prostaglandins. Appl Microbiol Biotechnol 1997, 47:199-206.

44. Hatae N, Sugimoto Y, Ichikawa A: Prostaglandin receptors: advances in the study of EP3 receptor signaling. J Biochem 2002, 131:781-784.

45. Sornasse $T$, Larenas PV, Davis KA: deVries JE, Yssel H: Differentiation and stability of $T$ Helper 1 and 2 cells derived from naive human neonatal $\mathrm{CD}^{+} \mathrm{T}$ cells, analyzed at the single-cell level. J Exp Med 1996, 184:473-483.

46. Delves PJ, Roitt IM: The immune system. Second of two parts. N Engl J Med 2000, 343:108-117.

47. van der Pouw Kraan TCTM, Boeije LCM, Smeenk RJT, Wijdenes J, Aarden LA: Prostaglandin- $\mathrm{E}_{2}$ is a potent inhibitor of human interleukin 12 production. J Exp Med 1995, 181:775-779.

48. Shibata Y, Henriksen RA, Honda I, Nakamura RM, Myrvik QN: Splenic $\mathrm{PGE}_{2}$-releasing macrophages regulate Th1 and Th2 immune responses in mice treated with heat-killed BCG. J Leukoc Biol 2005, 78:1281-1290.

49. Betz M, Fox BS: Prostaglandin $E_{2}$ inhibits production of Th1 lymphokines but not of Th2 lymphokines. J Immunol 1991, 146:108-113.

50. Noverr MC, Erb-Downward JR, Huffnagle GB: Production of eicosanoids and other oxylipins by pathogenic eukaryotic microbes. Clin Microbiol Rev 2003, 16:517-533.

51. Romani L: Innate and adaptive immunity in Candida albicans infections and saprophytism. J Leukoc Biol 2000, 68:175-179.

52. Santoni G, Boccanera M, Adriani D, Lucciarini R, Amantini C, Morrone S, Cassone A, De Bernardis F: Immune cell-mediated protection against vaginal candidiasis: Evidence for a major role of vaginal $\mathrm{CD} 4^{+} \mathrm{T}$ cells and possible participation of other local lymphocyte effectors. Infect Immun 2002, 70:4791-4797.
53. Schaller M, Mailhammer R, Korting HC: Cytokine expression induced by Candida albicans in a model of cutaneous candidosis based on reconstituted human epidermis. J Med Microbiol 2002, 51:672-676.

54. Cenci E, Mencacci A, Spaccapelo R, Tonnetti L, Mosci P, Enssle KH, Puccetti $P$, Romani $L$, Bistoni F: T helper cell type 1 (Th1)- and Th2-like responses are present in mice with gastric candidiasis but protective immunity is associated with Th1 development. J Infect Dis 1995, 171:1279-1288.

55. Montagnoli C, Sandini S, Bacci A, Romani L, La Valle R: Immunogenicity and protective effect of recombinant enolase of Candida albicans in a murine model of systemic candidiasis. Med Mycol 2004, 42:319-324.

56. Romagnoli G, Nisini R, Chiani P, Mariotti S, Teloni R, Cassone A, Torosantucci $A$ : The interaction of human dendritic cells with yeast and germ-tube forms of Candida albicans leads to efficient fungal processing, dendritic cell maturation, and acquisition of a Th1 response-promoting function. J Leukoc Biol 2004, 75:117-126.

57. Traynor TR, Kuziel WA, Toews GB, Huffnagle GB: CCR2 expression determines $\mathrm{T} 1$ versus $\mathrm{T} 2$ polarization during pulmonary Cryptococcus neoformans infection. J Immunol 2000, 164:2021-2027.

58. Osterholzer JJ, Surana R, Milam JE, Montano GT, Chen GH, Sonstein J, Curtis $J$, Huffnagle GB, Toews GB, Olszewski MA: Cryptococcal urease promotes the accumulation of immature dendritic cells and a non-protective T2 immune response within the lung. Am J Pathol 2009, 174:932-943.

59. Kundu G, Noverr MC: Exposure to host or fungal PGE ${ }_{2}$ abrogates protection following immunization with Candida-pulsed dendritic cells. Med Mycol 2011, 49:380-394.

60. Navarathna DHMLP, Nickerson KW, Duhamel GE, Jerrels TR, Petro TM: Exogenous farnesol interferes with the normal progression of cytokine expression during candidiasis in a mouse model. Infect Immun 2007, 75:4006-4011.

61. Smeekens SP, van de Veerdonk FL, van der Meer JWM, Kullberg BJ, Joosten $L A B$, Netea MG: The Candida Th17 response is dependent on mannanand $\beta$-glucan-induced prostaglandin $\mathrm{E}_{2}$. Int Immunol 2010, 22:889-895.

62. Smeekens $S P$, van de Veerdonk $F L$, Joosten $L A B$, Jacobs $L$, Jansen $T$, Williams $D L$, van der Meer JWM, Kullberg BJ, Netea MG: The classical CD14 ${ }^{++}$CD16 monocytes, but not the patrolling $\mathrm{CD} 14^{+} \mathrm{CD} 16^{+}$monocytes, promote Th17 responses to Candida albicans. Eur J Immunol 2011, 41:2915-2924.

63. Gagliardi MC, Teloni R, Mariotti S, Bromuro C, Chiani P, Romagnoli G, Giannoni F, Torosantucci A, Nisini R: Endogenous PGE 2 promotes the induction of human Th17 responses by fungal $\beta$-glucan. J Leukoc Biol 2010, 88:947-954.

64. Noverr MC, Huffnagle GB: Regulation of Candida albicans morphogenesis by fatty acid metabolites. Infect Immun 2004, 72:6206-6210.

65. Kalo-Klein A, Witkin SS: Prostaglandin $E_{2}$ enhances and gamma interferon inhibits germ tube formation in Candida albicans. Infect Immun 1990, 58:260-262.

66. Pelletier S, Dubé J, Villeneuve A, Gobeil F Jr, Yang Q, Battistini B, Guillemette $G$, Sirois P: Prostaglandin $E_{2}$ increases cyclic AMP and inhibits endothelin1 production/secretion by guinea-pig tracheal epithelial cells through EP4 receptors. Br J Pharmacol 2001, 132:999-1008.

67. Rooney PJ, Klein BS: Linking fungal morphogenesis with virulence. Cell Microbiol 2002, 4:127-137.

68. Ramage G, Saville SP, Thomas DP, López-Ribot JL: Candida biofilms: an update. Eukaryot Cell 2005, 4:633-638

69. Bhatt RK, Falck JR, Nigam S: Enantiospecific total synthesis of a novel arachidonic acid metabolite 3-hydroxy eicosatetraenoic acid. Tet Lett 1998, 39:249-252

70. Nigam S, Kumar SG, Kock JLF: Biological effects of 3-HETE, a novel compound of the yeast Dipodascopsis uninucleata, on mammalian cells. 10th International Conference on Prostaglandins and Related Compounds, Vienna, Austria. 1996

71. Nigam S, Schewe T, Kock JLF: 3(R)-Hydroxy oxylipins-a novel family of oxygenated polyenoic fatty acids of fungal origin. Adv Exp Med Biol 1999, 469:663-668.

72. Ciccoli R, Sahi S, Singh S, Prakash H, Zafiriou MP, Ishdorj G, Kock JLF, Nigam $\mathrm{S}$ : Oxygenation by COX-2 (cyclo-oxygenase-2) of 3-HETE (3-hydroxyeicosatetraenoic acid), a fungal mimetic of arachidonic acid, produces a cascade of novel bioactive 3- hydroxyeicosanoids. J Biochem 2005, 390:737-747.

73. Deva R, Shankaranarayanan P, Ciccoli R, Nigam S: Candida albicans induces selectively transcriptional activation of cyclooxygenase-2 in HeLa cells: 
Pivotal roles of toll-like receptors, p38 mitogen-activated protein kinase, and NF-KB. J Immunol 2003, 171:3047-3055.

74. Brooks PM, Day RO: Nonsteroidal antiinflammatory drugs-differences and similarities. Engl J Med 1991, 324:1716-1725.

75. Kock JLF, Sebolai OM, Pohl CH, van Wyk PWJ, Lodolo EJ: Oxylipin studies expose aspirin as antifungal. FEMS Yeast Res 2007, 7:1207-1217.

76. Strong R, Miller RA, Astle CM, Floyd RA, Flurkey K, Hensley KL, Javors MA, Leeuwenburgh C, Nelson JF, Ongini E, Nadon NL, Warner HR, Harrison DE: Nordihydroguaiaretic acid and aspirin increase lifespan of genetically heterogeneous male mice. Aging Cell 2008, 7:641-650.

77. de Quadros AU, Bini D, Pereira PAT, Moroni EG, Monteiro MC: Antifungal activity of some cyclooxygenase inhibitors on Candida albicans: $\mathrm{PGE}_{2}$-dependent mechanism. Folia Microbiol 2011, 56:349-352.

\section{doi:10.1186/1476-511X-11-100}

Cite this article as: Ells et al: Arachidonic acid metabolites in pathogenic yeasts. Lipids in Health and Disease 2012 11:100.

\section{Submit your next manuscript to BioMed Central and take full advantage of:}

- Convenient online submission

- Thorough peer review

- No space constraints or color figure charges

- Immediate publication on acceptance

- Inclusion in PubMed, CAS, Scopus and Google Scholar

- Research which is freely available for redistribution 